\title{
Differential Distribution of (Na, K)-ATPase $\alpha$ Isoforms in the Central Nervous System
}

\author{
Virginia Hieber, ${ }^{1}$ George J. Siegel, ${ }^{1,3}$ David J. Fink, ${ }^{1}$ Michael \\ W. Beaty, ${ }^{1}$ and Marina Mata ${ }^{1,2}$
}

Received August 10, 1990; accepted August 11, 1990

KEY WORDS: (Na, K)-ATPase; in situ hybridization; central nervous system.

\section{SUMMARY}

1. mRNA transcripts for three isoforms of the $\alpha$ subunit of $(\mathrm{Na}, \mathrm{K})$-ATPase have been previously identified in the rat nervous system and designated $\alpha 1, \alpha 2$ and $\alpha 3$.

2. In order to study the localization and expression of the different $\alpha$ isoform mRNAs on a regional and cellular level in the brain, we prepared probes from the unique $3^{\prime}$ untranslated region of rat $\alpha 1 \mathrm{cDNA}$ and from a segment containing a portion of the translated region of rat $\alpha 3$ cDNA. These probes were used in dot blot and in situ hybridization assays of rat brain.

3. $\alpha 1$ mRNA was found predominantly in cerebral cortex, dentate gyrus of hippocampus, and specific isolated brain-stem nuclei such as locus ceruleus and motor nuclei $\mathrm{V}$ and VII. In contrast $\alpha 3$ mRNA was found predominantly in pyramidal neurons in the deep layers of cerebral cortex, in both pyramidal and dentate gyrus neurons of the hippocampus, and in neurons of most subcortical structures of the thalamus, basal ganglia, and brain-stem nuclei.

4. In the cerebellum, Purkinje cells showed predominantly $\alpha 3$, as did stellate and basket cells. The granule cells contained predominantly $\alpha 1$.

5. These experiments show that mRNAs for both $\alpha 1$ and $\alpha 3$ isoforms of $(\mathrm{Na}, \mathrm{K})$-ATPase are found in neurons of the CNS. The isoforms have unique cellular and regional distributions, which in some cases overlap.

\footnotetext{
${ }^{1}$ GRECC Neurology Research Laboratory, VA Medical Center, and Neurochemistry Laboratory, Department of Neurology, University of Michigan, Ann Arbor, Michigan.

${ }^{2}$ To whom correspondence should be addressed at Department of Neurology, 2215 Fuller Road, Ann Arbor, Michigan 48105.

${ }^{3}$ Current address: Hines VA Medical Center and Department of Neurology, Loyola University Medical Center, Maywood, Illinois.
} 


\section{INTRODUCTION}

(Na, K)-ATPase accounts for at least $30 \%$ of the resting energy metabolism of the brain, utilizing energy derived from the hydrolysis of ATP to pump $\mathrm{Na}^{+}$out of cells in exchange for $\mathrm{K}^{+}$(Albers et al., 1989). Three isoforms of the $\alpha$ (catalytic) subunit of ( $\mathrm{Na}, \mathrm{K})$-ATPase have been identified in rat brain and designated $\alpha 1, \alpha 2$, and $\alpha 3$ (Shull et al., 1986; Herrera et al., 1987; Urayama et al., 1989; Shyjan and Levenson, 1989). $\alpha 1$ is identical to the isoform found in kidney, and in rodents, $\alpha 1$ has a lower affinity than $\alpha 2$ or $\alpha 3$ for ouabain (Hara $e t$ al., 1989; Price and Lingrel, 1988; Urayama and Sweadner, 1988). $\alpha 3$ isolated from rat pineal gland has a higher affinity for $\mathrm{Na}^{+}$than has kidney $\alpha 1$ (Shyjan et al., 1990). The $\mathrm{Na}^{+}$affinity for $\alpha 2$ in rat adipocytes is increased by insulin (Lytton, 1985). $\alpha 2$ and $\alpha 3$ are not found in kidney, but are found in other tissues in addition to brain and show tissue-specific developmental expression (Orlowski and Lingrel, 1988). The three $\alpha$ isoforms are products of three distinct genes (Yang-Feng et al., 1988), and the isoforms in myocardial cells in culture are differentially regulated by hormones (Orlowski and Lingrel, 1990). These observations suggest that the isoforms may be separately adapted for special regulatory features in different cell types.

The three different $\alpha$ isoforms in rat have substantial homology in nucleic acid sequence and corresponding homology in the translated amino acid sequences (Shull et al., 1986; Herrera et al., 1987). However, the untranslated regions of the mRNAs are unique. We have exploited this feature to create a ${ }^{35} \mathrm{~S}$-labeled riboprobe from the $3^{\prime}$ untranslated region of $\alpha 1$ cDNA. We have also created a riboprobe to a relatively distinct region of the translated $\alpha 3$ cDNA sequence. This riboprobe is proved not to cross-react with the $\alpha 1$ mRNA by in situ hybridization analysis of spinal cord and peripheral nerve and by dot blot analysis of kidney and peripheral nerve (Mata et al., in press). We have now used these specific probes to study the differential distribution of $\alpha 1$ and $\alpha 3$ isoform mRNAs in the brain of the rat.

In order to test hypotheses regarding the special functions of the isoforms, it is necessary to determine their regional and cellular distribution. There are very few data regarding isoform-specific mRNA expression in brain. Schneider et al. (1988) employed a probe for $\alpha 3 \mathrm{mRNA}$ and reported localization in neuron-rich structures in forebrain and in Purkinje cells in rat cerebellum. Hieber et al. (1989) used a probe for $\alpha 1$ mRNA to study distribution on a cellular level in mouse cerebellum and retina. Filuk et al. (1989) used oligonucleotide probes for $\alpha 1, \alpha 2$, and $\alpha 3$ to map their regional distribution in rat cerebrum. They found $\alpha 3$ mRNA in deep cortical layers and subcortical structures, and $\alpha 1$ mRNA mainly in superficial layers of cortex but not in subcortical nuclei. Our results confirm this pattern and extend these previously reported results to show a unique distribution also in the cerebellum and brain stem and to define several distinct normal populations which express either $\alpha 1$ and/or $\alpha 3$ mRNAs.

\section{METHODS}

Production of Riboprobes. Cloned rat $\alpha$ isoform cDNAs, graciously provided to us by Dr. Robert Levenson (Yale University) and by Dr. Jerry Lingrel 
(University of Cincinnati College of Medicine), were used to prepare subclones containing the $3^{\prime}$ untranslated region of the $\alpha 1$ isoform cDNA and a segment of the translated region of $\alpha 3$ isoform cDNA. A 203-bp Bam H1-Pst 1 restriction fragment from the $3^{\prime}$ end of the $\alpha 1$ cDNA and a 416-bp Pst1-EcoR1 fragment containing a portion of the translated region of the $\alpha 3 \mathrm{cDNA}$ were subcloned into the vector pGEM4. ${ }^{35} \mathrm{~S}$-Labeled riboprobes were prepared by transcription of the linearized clones in the presence of ${ }^{35} \mathrm{~S}$-labeled UTP for in situ hybridization studies. ${ }^{32} \mathrm{P}$-Labeled probes for use in dot-blot studies were prepared in a similar manner by transcription in the presence of ${ }^{32} \mathrm{P}$-UTP. Because the $3^{\prime}$ untranslated region of the $\alpha 1$ isoform is a unique sequence, this riboprobe is specific for $\alpha 1$. The translated region of the $\alpha 3$ isoform used to produce the riboprobe has $70 \%$ homology with $\alpha 1$, but evidence obtained with spinal cord and peripheral nerve (Mata et al., in press) as well as additional data in brain presented below indicates that under our hybridization conditions, the riboprobe recognizes $\alpha 3$ mRNA specifically.

Dot Blotting. RNA dot blotting was carried out essentially as described previously (Bevilacqua et al., 1988). Total cellular RNA was isolated from cortex, basal ganglia, brain stem, and cerebellum using a commercially available kit (RNAzol B, Cinna/Biotecx Laboratories, Texas) and spotted on GeneScreen membranes. RNA was isolated from kidney as reported earlier (Hieber et al., 1989). Hybridization to ${ }^{32} \mathrm{P}$-labeled RNA probes was carried out at $70^{\circ} \mathrm{C}$ with prehybridization, hybridization, and subsequent washing of filters as described previously (Bevilacqua et al., 1988), except that these procedures were all carried out at $70^{\circ} \mathrm{C}$. Autoradiograms of the filters were produced on Kodak XAR film exposed at $-80^{\circ} \mathrm{C}$.

In Situ Hybridization. In situ hybridization was performed essentially as described by Watson et al. (1987). Briefly, animals were sacrificed by decapitation and $10-\mu \mathrm{m}$ cryostat sections of brain were covered with an aliquot of hybridization buffer containing approximately $5 \times 10^{4} \mathrm{cpm} / \mu \mathrm{l}$ of ${ }^{35} \mathrm{~S}$-labeled RNA probe and sealed with coverslips. Sections were hybridized for $21 \mathrm{hr}$ at $55^{\circ} \mathrm{C}$. After removal of the labeled probe, the sections were rinsed twice with $2 \times$ SSC at room temperature for $30 \mathrm{~min}$, once with $50 \%$ formamide in $2 \times \mathrm{SSC}$ at $55^{\circ} \mathrm{C}$ for 30 $\min$, treated with $50 \mu \mathrm{g} / \mathrm{ml} \mathrm{RNase} A$ for $30 \mathrm{~min}$ at $37^{\circ} \mathrm{C}$, washed with $0.5 M \mathrm{NaCl}$, $10 \mathrm{mM}$ Tris, $1 \mathrm{~m} M$ EDTA for $30 \mathrm{~min}$ at $60^{\circ} \mathrm{C}$, and finally, rinsed with $2 \times \mathrm{SSC}$, water, and a graded series of alcohols. The slides were initially exposed to Kodak XAR film for times ranging from 3 to 10 days, before being dipped in emulsion and developed. This allowed both examination of autoradiographic images on film and light microscopic examination of the slides. The X-ray film was analyzed using an Imaging Resources Inc (London, Ont.) image analyzer and digitized images were photographed. Developed slides were counterstained with cresyl violet and photographed under bright-field and dark-field optics.

\section{RESULTS}

The in situ hybridization gave distinct autoradiographic patterns for the two different isoforms. In the cerebral hemispheres, $\alpha 1$ labeled predominantly cortex, hippocampus, and habenula (Fig. 1), while $\alpha 3$ labeled all these structures and the 


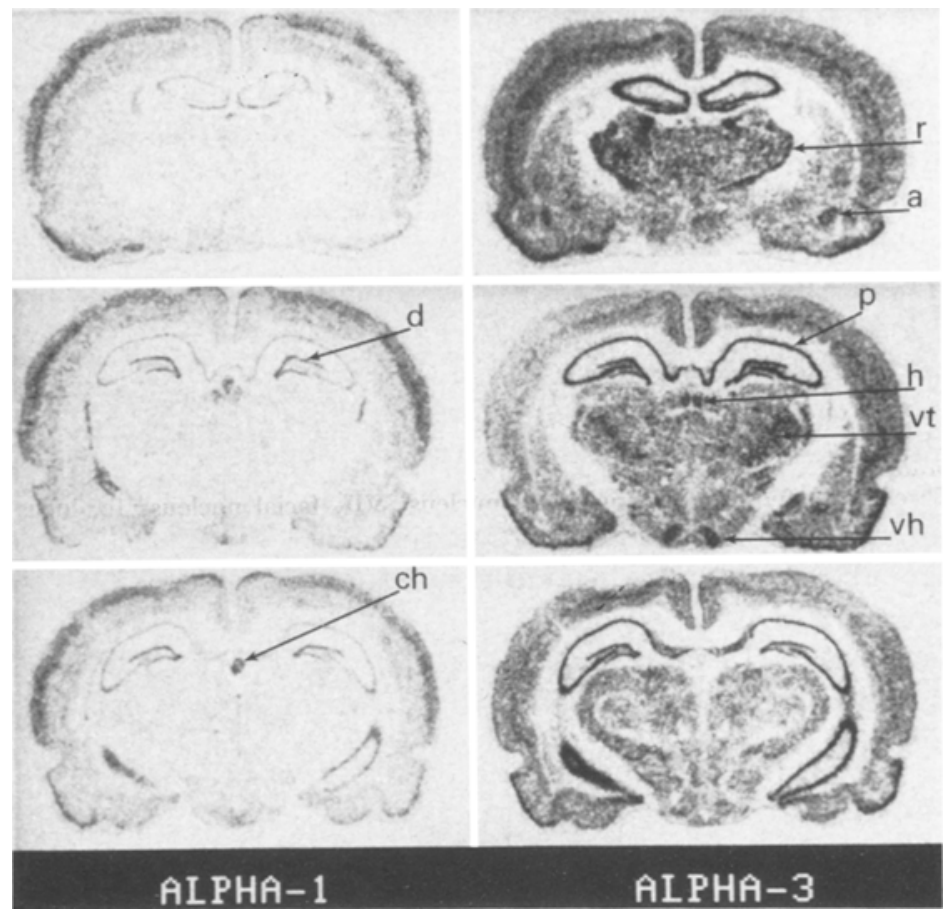

Fig. 1. Computer-digitized image of film autoradiogram of rat cerebral hemisphere in situ hybridization with ${ }^{35}$ S-labeled $\alpha 1$ and $\alpha 3$ riboprobes. The film was exposed overnight. $d$, dentate gyrus of hippocampus; $p$, pyramidal cells of hippocampus; $r$, reticular nucleus of thalamus; $a$, amygdala; $h$, habenula; vt, ventral posterior nucleus of thalamus; vh, ventromedial nucleus of hypothalamus; ch, choroid plexus.

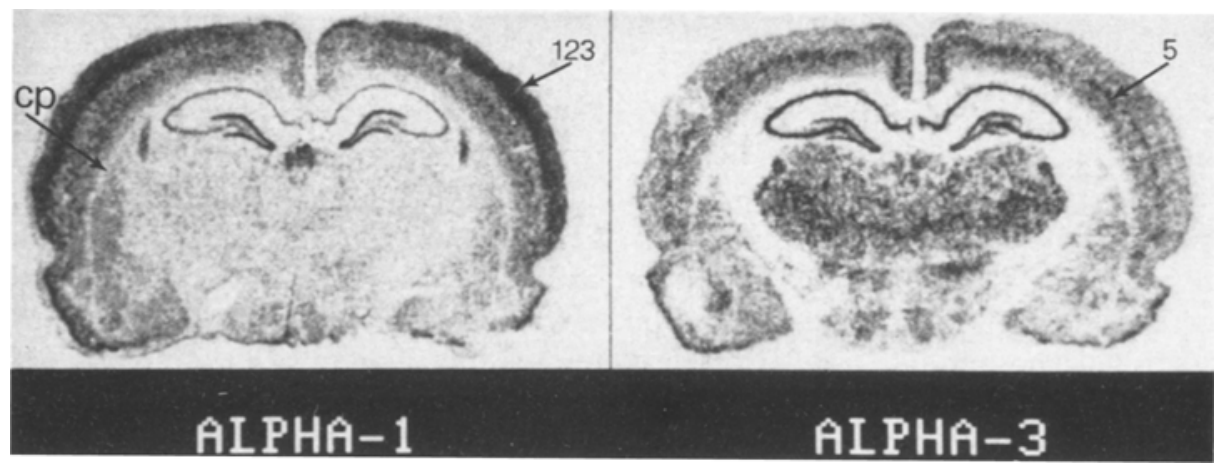

Fig. 2. Computer-digitized image of film autoradiogram of rat cerebral hemisphere in situ hybridization with ${ }^{35} \mathrm{~S} \alpha 1$ and $\alpha 3$ riboprobes. The $\alpha 1$ hybridization was exposed for 4 days and the $\alpha 3$ hybridization overnight in order to obtain images of equivalent density to facilitate comparison of the distributions. cp, caudate-putamen; 123 , layers of cortex; 5 , layer of cortex. 


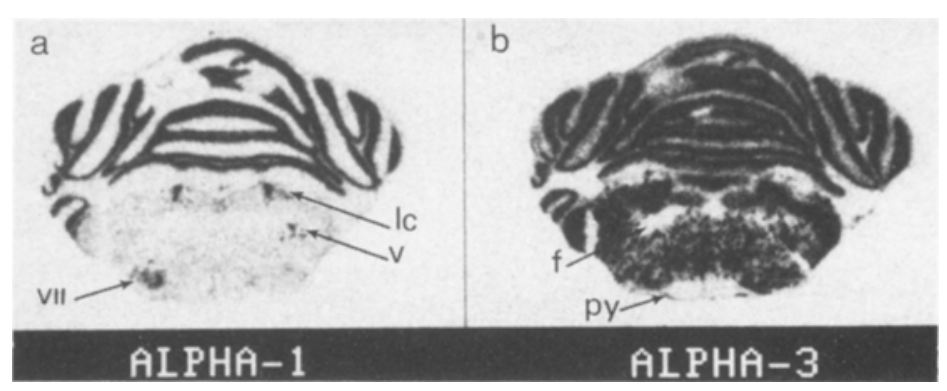

Fig. 3. Computer-digitized image of film autoradiogram of cerebellum and brain stem in situ hybridization with ${ }^{35}$ S-labeled $\alpha 1$ and $\alpha 3$ riboprobes. Three-day exposure. V, trigeminal nucleus; VII, facial nucleus; $1 \mathrm{c}$, locus ceruleus; $f$, facial nerve; py, pyramids.

deep nuclei including striatum, thalamus, and amygdala with similar intensity (Fig. 1). In the cerebral cortex, the $\alpha 1$ probe labeled layers 1,2 , and 3 more densely than deeper layers, while the $\alpha 3$ probe labeled layer 5 more intensely than the more superficial layers (Fig. 2). In the hippocampus, $\alpha 1$ labeling was more intense in the dentate gyrus than in the pyramidal cells, while $\alpha 3$ labeling was equally intense in both dentate gyrus and pyramidal cells (Figs. 1 and 2). With a longer exposure it could be seen that the $\alpha 1$ probe labeled the caudate-putamen more intensely than the pallidum, while the $\alpha 3$ probe labeled the caudate-putamen and pallidum equally (data not shown).

In the brain stem, most neurons were strongly labeled with the $\alpha 3$ probe (Fig. 3b). Some structures, such as the substantia nigra pars compacta, the red nucleus, and the motor nucleus of III, were particularly intensely labeled with this probe. In contrast, dense $\alpha 1$ labeling was seen in neurons of only a few, isolated brain-stem nuclei including the locus ceruleus, the motor nucleus of $\mathrm{V}$, and the VII nerve nucleus (Fig. 3a).

In the cerebellum, the $\alpha 3$ probe labeled Purkinje cells most strongly. Basket and stellate cells were also labeled, while little label was seen in the granule cell layer (Figs. $4 \mathrm{~b}$ and d). In comparison, $\alpha 1$ preferentially labeled the granule cell layer (Fig. 4a and 4c).

In all of the brain regions examined, in situ hybridization signal was localized predominantly over neuronal perikarya with both probes (Fig. 5). The only strongly labeled nonneuronal structure was the ependyma of the choroid plexus, which was labeled exclusively with the $\alpha 1$ probe (Fig. 1).

Dot-blot analysis of cortex and brain stem showed both $\alpha 1$ and $\alpha 3$ mRNAs in these neural structures. Kidney RNA was labeled with the $\alpha 1$ probe but was not labeled with the $\alpha 3$ probe (Fig. 6).

\section{DISCUSSION}

These results confirm unique distributions for $\alpha 1$ and $\alpha 3$ isoforms of the catalytic subunit of $(\mathrm{Na}, \mathrm{K})$-ATPase in the central nervous system. 

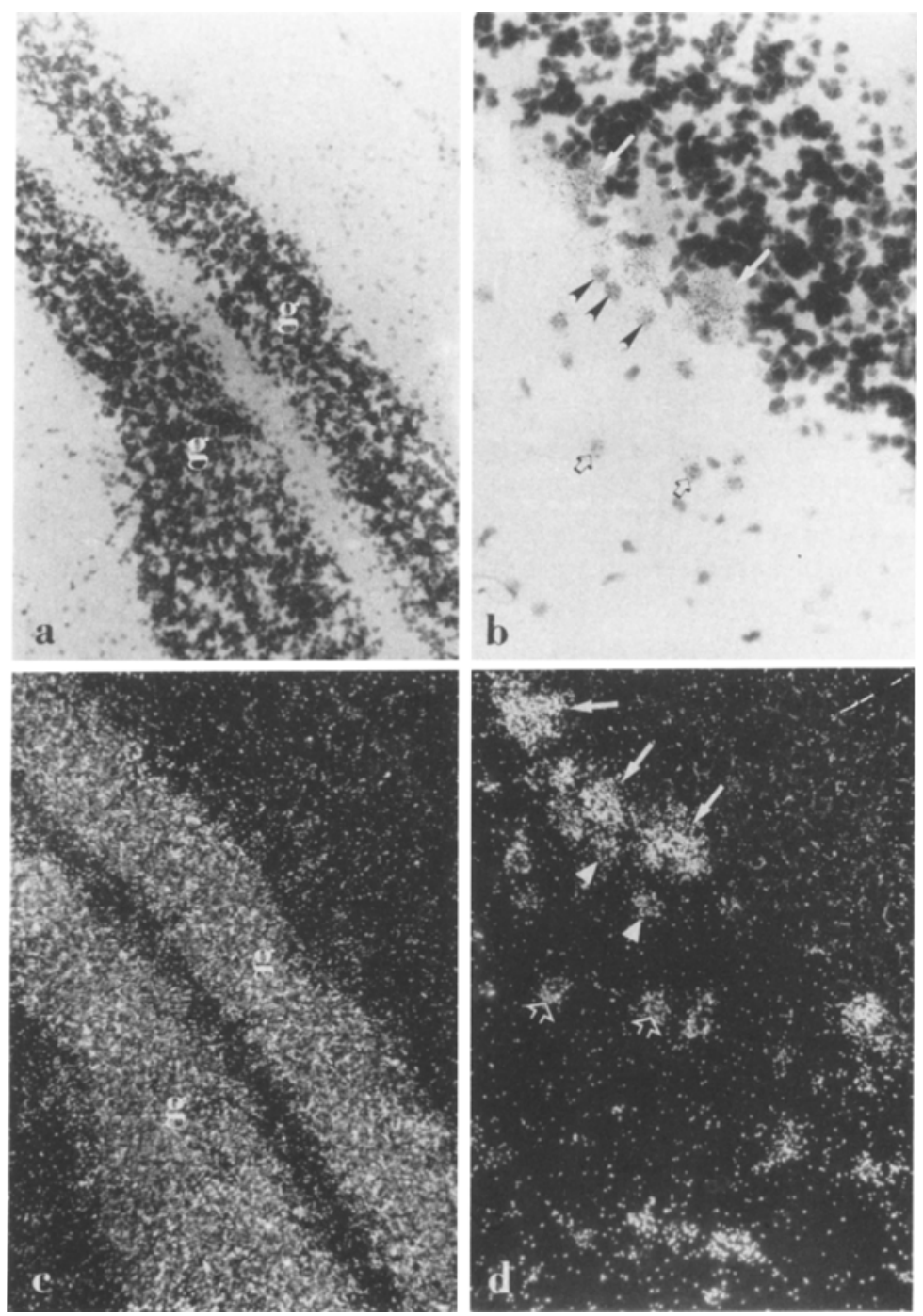

Fig. 4. Microscopic view of in situ hybridization with $\alpha 1$ (a and c) and $\alpha 3$ (b and d). ${ }^{35}$ S-labeled riboprobes seen in bright field ( $a$ and $b$ ) and dark field (c and d). g, granule cell layer; white arrows, Purkinje cells; arrowheads, basket cells; open arrows, stellate cells. Exposure time, 1 week. $(\mathrm{a}, \mathrm{c}) \times 312$ and (b,d) $\times 500$; reduced $40 \%$ for reproduction.

Schneider et al. (1988) used a riboprobe prepared from an $\alpha 3$ cDNA corresponding to the full-length coding region to study $\alpha 3$ distribution in adult rat brain cryostat sections and also found $\alpha 3$ in neuron-rich regions of brain including cortex, thalamus, hippocampal dentate gyrus, habenula, and the Purkinje cells of cerebellum. The distribution suggested that $\alpha 3$ is most abundantly expressed by "specific major neurons" of adult brain (Schneider et al., 1988). 


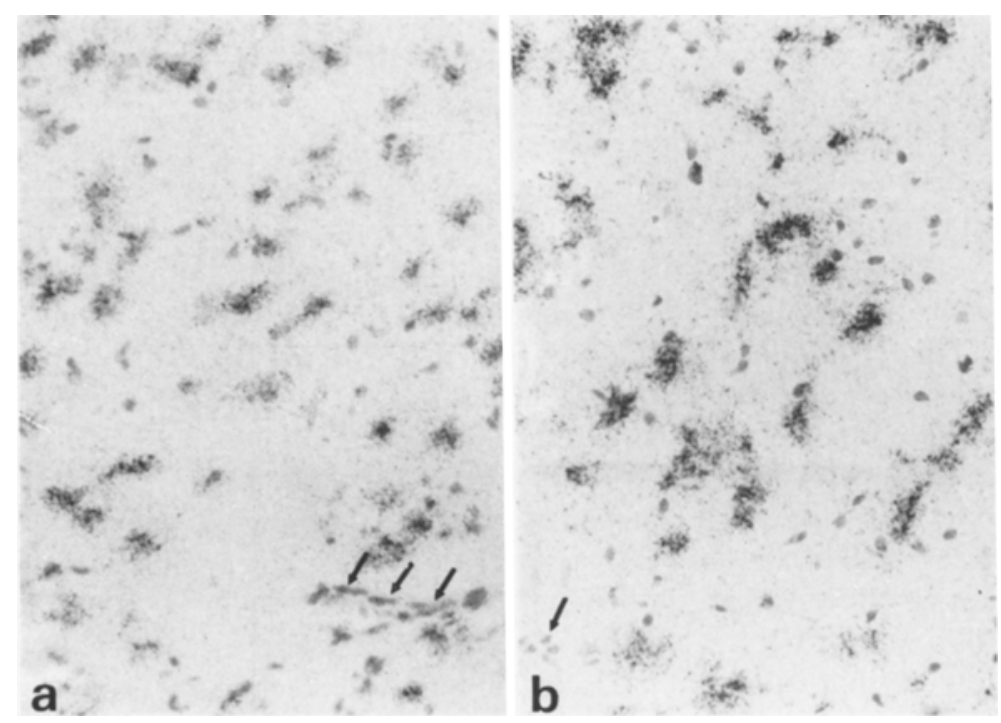

Fig. 5. High-power microscopic views of in situ hybridization of cortex with $\alpha 1{ }^{35} \mathrm{~S}$-labeled riboprobe (a) and thalamus with $\alpha 3{ }^{35} \mathrm{~S}$-labeled riboprobe (b). Most of the grains are clustered over neuronal nuclei. Arrows, capillary endothelial cells. Exposure time, 1 week. $\times 500$; reduced $40 \%$ for reproduction.

Hieber et al. (1989) used a riboprobe prepared from a 483-bp cDNA insert from the coding region of $\alpha 1$ to study $\alpha$ isoform distribution in the cerebellum. High levels of expression were found in stellate, basket, and granule cells, as well as in Purkinje cells. However, the $\alpha 1$ probe used in that study was constructed from a highly conserved region of the coding sequence, and the signal may have represented cross-reactivity with $\alpha 3$ mRNA under in situ hybridization conditions.

Filuk et al. (1989) using synthetic oligonucleotide probes to obtain regional maps in the rat cerebrum, found $\alpha 1$ mRNA mainly in layers 2 and 3 of cortex. In hippocampus, granule cells contained more $\alpha 1$ than pyramidal neurons did. $\alpha 1$ was relatively sparse in deep nuclei. $\alpha 2$ and $\alpha 3$ mRNAs were diffusely distributed.

Our results with the longer riboprobes confirm the main observations in rat cerebrum obtained with the synthetic oligonucleotide probes for $\alpha 1$ and $\alpha 3$ (Filuk et al., 1989). As reported in the earlier study, $\alpha 1$ is expressed mainly in the more superficial layers of cortex and in the granule cells of the dentate gyrus, while $\alpha 3$ is expressed at high levels in deeper cortical laminae, in thalamic nuclei, striatum, and hippocampal granule and pyramidal cells. We did not confirm a higher level of expression of either isoform in pyriform cortex which was reported earlier (Filuk et al., 1989). Prior studies of brain stem are not available for comparison. Our results demonstrate a marked separation of isoform distribution, with $\alpha 3$ in most brain-stem nuclei and $\alpha 1$ in only a few, isolated, nuclei. In the cerebellar cortex, in contrast to earlier data (Schneider et al., 1988), $\alpha 3$ is expressed in 
neurons of all layers but principally in neurons of the Purkinje and molecular layers. The present data with a specific $\alpha 1$ probe show that in cerebellar cortex, $\alpha 1$ is expressed mainly in granule cell layer.

The $\alpha 3$ probe which we have constructed has some potential to cross-react with $\alpha 1$ mRNA, since it contains a portion of the translated region which has substantial homology with the $\alpha 1$ sequence. In dot-blot analysis, the $\alpha 3$ probe did not cross-react with kidney mRNA, which contains $\alpha 1$ but not $\alpha 3$ isoform (Fig. 6). A stronger argument for the specificity of the two probes is found in comparing their unique distributions seen with in situ hybridization in similar sections. For example, the $\alpha 1$ probe but not the $\alpha 3$ probe labels the ependyma of choroid plexus (Fig. 2). In the brain stem, the $\alpha 3$ probe labels neuronal perikarya in most nuclei, while the $\alpha 1$ probe labels neuronal perikarya only in a few discrete nuclei. Similarly, unique distributions of $\alpha 1$ and $\alpha 3$ labeling with these probes were seen in the spinal cord and dorsal root ganglia of the peripheral nervous system (Mata et al., in press).

The absence of detectable signal with either probe in astrocytes, oligodendroglia, and vascular endothelial cells under these conditions suggests that the amount of (Na, K)-ATPase mRNA in these cells is much less than that found in neurons. It does not imply that ( $\mathrm{Na}, \mathrm{K})$-ATPase is not present in these cells. In spinal cord, for example, $\alpha 1$ signal was detected in white matter tracts after long exposure times of 4 to 6 weeks (Mata et al., in press). Also, additional isoform mRNAs not detected with $\alpha 1$ and $\alpha 3$ probes may be present. It should also be noted that while it is valid to compare the amount of labeling between cells or regions using a single probe hybridized under identical conditions, it is not possible to infer the relative amounts of different mRNAs by comparison of the amount of labeling produced by two different probes.

Both $\alpha 1$ and $\alpha 3$ polypeptides can be identified in cortex, brain stem, and cerebellum by Western blot using monoclonal antibodies specific for each isoform (Urayama et al., 1989). These results are consistent with our dot-blot results for mRNA but are not informative regarding regional and cellular distribution of the isoforms. Our in situ results indicate that both $\alpha 1$ and $\alpha 3$ mRNAs are found in neurons but that their proportions vary in different regions. Cultured astrocytes appear to express only $\alpha 1$ polypeptide (Sweadner, 1979) as defined by gel electrophoresis and ouabain affinity. Axolemmal preparations from rat brain stem contain only $\alpha 3$ polypeptide (Sweadner, 1988). The axonal abundance of $\alpha 3$ polypeptide is probably due to the preponderance of $\alpha 3 \mathrm{mRNA}$-containing neurons in the brain stem as seen in the current in situ analysis, and tracts derived from cortical $\alpha 3$ mRNA-containing neurons. Immunocytochemical studies using monoclonal antibodies specific for $\alpha$ subunit isoform polypeptides have been published only for retina and optic nerve (McGrail and Sweadner, 1989), cochlea

Fig. 6. Dot blot of brain stem (B), cortex (C), and kidney $(\mathrm{K})$ with ${ }^{32} \mathrm{P}$-labeled probe. Left, $\alpha 1$; right, $\alpha 3 ; 5,2.5$, and $0.5 \mu \mathrm{g}$ total RNA as indicated.

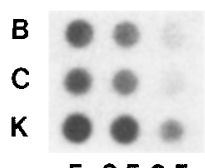

52.50 .5

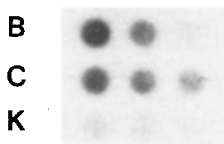

$\begin{array}{lll}5 & 2.5 & 0.5\end{array}$ 
(Schulte and Adams, 1990), and vestibular organ (Spicer et al., 1990). Application of these antibodies to the CNS will be of importance in localizing the translated products, particularly in cells containing mRNAs for multiple isoforms.

Previous work has indicated some biochemical differences between the two isoforms. Rodent $\alpha 1$ has a lower affinity both for ouabain and for $\mathrm{Na}^{+}$than has $\alpha 3$ (Sweadner, 1979, 1989; Urayama and Sweadner, 1988). While the functional difference between these isoforms has not been defined, the presence of the two different isoforms in various proportions in distinct brain regions and in distinct neuronal cell types confirms the suggestion that they subserve functional differences related to specific neuronal properties. These may relate to regulation of $\mathrm{Na}^{+}$and $\mathrm{K}^{+}$gradients at different set points, which may in turn be related to special characteristics of membrane potential, flux of other ions $\left(\mathrm{Ca}^{2+}, \mathrm{H}^{+}\right)$, and solutes dependent on these gradients (amino acids, glucose) or neurotransmitter systems.

The current study defines the neuronal distribution of isoform-specific $\alpha 1$ and $\alpha 3$ mRNAs in brain and can be used to identify alterations in $\alpha$ isoform mRNA expression in pathologic conditions and in normal development and aging.

\section{ACKNOWLEDGMENTS}

We gratefully acknowledge the expert advice of Dr. John B. Penney in analysis of the data. This work was supported by VA Merit Review Grants (M.M. and D.J.F.), the NINDS (Grant NS2777-01; D.J.F.), and the Biomedical Research Council and Michigan Diabetes Research and Training Center of the University of Michigan (G.J.S.). Portions of this work were presented in abstract form to the Society for Neuroscience in October 1990.

\section{REFERENCES}

Albers, R. W., Siegel, G. J., and Stahl, W. L. (1989). Membrane transport. In Basic Neurochemistry 4th edition (G. J. Siegel, B. W. Agranoff, R. W. Albers, and P. B. Molinoff, Eds.), Raven Press, New York, pp. 49-70.

Bevilacqua, A., Erickson, R. P., and Hieber, V. (1988). Antisense RNA inhibits endogenous gene expression in mouse preimplantation embryos: Lack of double-stranded RNA "melting" activity. Proc. Natl. Acad. Sci. USA 85:831-835.

Filuk, P. E., Miller, M. A., Dorsa, D. M., and Stahl, W. L. (1989). Localization of messenger RNA encoding isoforms of the catalytic subunit of $\mathrm{Na}, \mathrm{K}$-ATPase in rat brain by in situ hybridization histochemistry. Neurosci. Res. Comm. 5:155-162.

Hara, Y., Ohtsubo, M., Kojima, T., Noguch, S., Nakao, M., and Kawamura, M. (1989). Expression of active alpha-3 subunit of rat brain $\mathrm{Na}^{+}, \mathrm{K}^{+}$-ATPase from the messenger RNA injected into xenopus oocytes. Biochem. Biophys. Res. Commun. 163:102-105.

Herrera, V. L., Emanuel, J. R., Ruiz Opazo, N., Levenson, R., and Nadal Ginard, B. (1987). Three differentially expressed $\mathrm{Na}$, K-ATPase alpha subunit isoforms: Structural and functional implications. J. Cell Biol. 105:1855-1865.

Hieber, V., Siegel, G. J., Desmond, T., Lee-Hwa Liu, J., and Ernst, S. A. (1989). Na, K-ATPase: Comparison of the cellular localization of alpha-subunit mRNA and polypeptide in mouse cerebellum, retina, and kidney. J. Neurosci. Res. 23:9-20. 
Lytton, J. (1985). Insulin affects the sodium affinity of the rat adipocyte (Na, K)-ATPase. J. Biol. Chem. 260:10075-10080.

Mata, M., Siegel, G. J., Hieber, V., Beaty, M. W., and Fink, D. J. Differential distribution of (Na, K)-ATPase $\alpha$ isoform mRNAs in the peripheral nervous system. Brain Res. (in press).

McGrail, K. M., and Sweadner, K. J. (1989). Complex expression patterns for the Na, K ${ }^{+}$ATPase isoforms in retina and optic nerve. Eur. J. Neurosci. 2:170-176.

Orlowski, J., and Lingrel, J. B. (1988). Tissue-specific and developmental regulation of rat $\mathrm{Na}$, K-ATPase catalytic alpha isoform and beta subunit mRNAs. J. Biol. Chem. 263:10436-10442.

Orlowski, J., and Lingrel, J. B. (1990). Thyroid and glucocorticoid hormones regulate expression of multiple $\mathrm{Na}, \mathrm{K}$-ATPase genes in cultured neonatal rat cardiac myocytes. J. Biol. Chem. 265:3462-3470.

Price, E. M., and Lingrel, J. B. (1988). Structure-function relationships in the Na, K-ATPase alpha subunit: Site-directed mutagenesis of glutamine-11 to arginine and asparagine-122 to aspartic acid generates a ouabain resistant enzyme. Biochemistry 27:8400-8408.

Schneider, J. W., Mercer, R. W., Gilmore-Hebert, M., Utset, M. F., Lai, C., Greene, A., and Benz, E. J. (1988). Tissue specificity, localization in brain, and cell-free translation of mRNA encoding the A3 isoform of $\mathrm{Na}^{+}, \mathrm{K}^{+}$-ATPase. Proc. Natl. Acad. Sci. USA 85:284-288.

Schulte, B. A., and Adams, J. C. (1990). Distribution of immunoreactive $\mathrm{Na}^{+}, \mathrm{K}^{+}-$ATPase in gerbil cochlea. J. Histochem. Cytochem. 37:127-134.

Shull, G. E., Greeb, J., and Lingrel, J. B. (1986). Molecular cloning of three distinct forms of the $\mathrm{Na}^{+}, \mathrm{K}^{+}$-ATPase alpha-subunit from rat brain. Biochemistry 25:8125-8132.

Shyjan, A. W., and Levenson, R. (1989). Antisera specific for the alpha1, alpha2, alpha3, and beta subunits of the $\mathrm{Na}, \mathrm{K}$-ATPase: Differential expression of alpha and beta subunits in rat tissue membranes. Biochemistry 28:4531-4535.

Shyjan, A. W., Cena, V., Klein, D. C., and Levenson, R. (1990). Differential expression and enzymatic properties of the $\mathrm{Na}, \mathrm{K}$-ATPase alpha3 isoenzyme in rat pineal glands. Proc. Natl. Acad. Sci. USA, 87:1178-1182.

Spicer, S. F., Schulte, B. A., and Adams, J. C. (1990). Immunolocalization of $\mathrm{Na}^{+}, \mathrm{K}^{+}$-ATPase and carbonic anhydrase in the gerbil vestibular system. Hear. Res. 43:205-217.

Sweadner, K. J. (1979). Two molecular forms of $\left(\mathrm{Na}^{+}+\mathrm{K}^{+}\right)$-stimulated ATPase in brain. Separation and difference in affinity for strophanthidin. J. Biol. Chem. 254:6060-6067.

Sweadner, K. J. (1988). Preparation of the alpha(+) isozyme of the $\mathrm{Na}^{+}, \mathrm{K}^{+}$-ATPase from mammalian axolemma. Methods Enzymol. 156:65-71.

Sweadner, K. J. (1989). Isozymes of the Na/K-ATPase. Biochim. Biophys. Acta 988:185-220.

Urayama, O., and Sweadner, K. J. (1988). Ouabain sensitivity of the alpha 3 isozyme of rat $\mathrm{Na}$, K-ATPase. Biochem. Biophys. Res. Commun. 156:796-800.

Urayama, O., Shutt, H., and Sweadner, K. J. (1989). Identification of three isozyme proteins of the catalytic subunit of the Na, K-ATPase in rat brain. J. Biol. Chem. 264:8271-8280.

Watson, S. J., Sherman, J. G., Kelsey, J. E., Burke, S., and Akil, H. (1987). Anatomical localization of mRNA: In situ hybridization of neuropeptide systems. In In Situ Hybridization: Applications to Neurobiology (K. L. Valentino, J. H. Eberwine, and J. D. Barchas, Eds.), Oxford University Press, New York, pp. 126-145.

Yang-Feng, T. L., Schneider, J. W., Lindgren, V., Shull, M. M., Benz, E. J., Lingrel, J. B., and Francke, U. (1988). Chromosomal localization of human Na, K-ATPase alpha and beta subunit genes. Genomics 2:128-138. 